\title{
Forum
}

Psychological Medicine (2013).

doi:10.1017/S0033291713000895

\section{Forum \\ A modern name for schizophrenia (PSS) would diminish self-stigma}

The first country to change the name of schizophrenia was Japan (Sato, 2006). The campaign began in 1993 after an initiative by the family movement. They approached the Japanese Society of Psychiatry and Neurology (JSPN) to find a new name for Seishin Bunretsu Byo (split mind). This was but a part of the programme to counter the misunderstandings and prejudices surrounding the concept of schizophrenia. After a series of polls, symposia and study days the committee of the JSPN responsible for the image of schizophrenia chose the name Togo-Shitcho Sho (integration dysregulation syndrome). After a public hearing the term was adopted. The result was that patients were better able to accept the diagnosis. The stigma associated with the old terminology dates back to the frightening treatment of people with schizophrenia and the poor course of the disease at the end of the nineteenth century and the beginning of the twentieth century. The psychiatric application of chlorpromazine had not yet then been discovered.

The stigma diminished as a result of the name change and accompanying dissemination of factual information. The name Togo-Shitcho Sho was more acceptable to patients than 'split mind': psychiatrists were able to inform their patients of the diagnosis in a more acceptable way, resulting in better adherence and less relapse; patients were more willing to seek help; there were fewer suicides, indicating that patients had a healthier self-image and less self-stigma.

Evans-Lacko et al. (2012) have shown that there is a trend for patients' self-stigma to arise from internalization of surrounding stigmatizing attitudes. By statistics the subjective is made objective: Evans-Lacko et al. conclude from datasets from the Eurobarometer survey and the GAMIAN-Europe study that there is a connection between public stigmatizing of mental illness and patients' fragile self-appraisal: patients are prone to internalize the stigma attached to mental health problems by the general public. Furthermore, it stands to reason that if we do not accept ourselves, warts and all, our mental health will not get any better. As a leading self-disclosed publisher of a magazine on schizophrenia, Sz magazine, Bill MacPhee, says: 'Recovery is not wanting to be anyone else than who you are today' (cited with permission; http://www. mentalwellnesstoday.com/).

We as patients/consumers/service users welcome objective evidence-based research into the public stigma attached to mental health problems. Objective evidence-based conclusions are helpful in shaping our campaigning and for our understanding of our own subjective experience. We submit that the reverse can also be true: subjective experience can enlighten the research data.

We as patients are aware of the insidiousness of internalizing hostile public attitudes. Our response as members of Anoiksis, the Dutch association of and for people with a susceptibility to psychosis, is to provide open and honest self-portraits and information to the public about our condition as people with schizophrenia. Like the English Time to Change campaign (see London \& Evans-Lacko, 2010; Thornicroft, 2011) we at Anoiksis are working mainly through direct personal contact but also through the media. Corrigan et al. (2001) have shown that replacing myths about mental illness with accurate conceptions by education works: it is almost as effective as person-to-person contact in improving attributions about schizophrenia and other severe mental illnesses. (In that study protest yielded no significant changes in attributions!)

Anoiksis has recently produced a one-off glossy magazine SKIZ'O: Het NORMAALSTE magazine van Nederland (SKIZ'O: The most NORMAL magazine of the Netherlands) (Muis, 2010) and a photo album with interviews, Meer dan dat... 10 portretten van mensen met schizofrenie (More than that...10 portraits of people with schizophrenia) (Muis, 2011). Some of our Anoiksis members have given open and honest selfdisclosing interviews to journals and national daily newspapers and made radio and TV appearances.

We are providing insights into the condition in conjunction with a campaign to change the label 'schizophrenia'. That label we experience as encapsulating the hindrance to our self-acceptance. It stands in the way of a healthy self-regard. It is not a question of exaggerating our self-esteem, but of our acceptance of ourselves as we are. It is no good fudging the negative aspects of our condition. Honest 'disclosure and positive social contact', as London \& Evans-Lacko (2010) point out, is the most effective means of better informing the public about what our mental illness actually consists in (see also Thornicroft, 2011). We as patients find that the process of disclosure as well as gaining some understanding from the public helps to improve 
the self-regard of the individual. However, we as members of Anoiksis feel hamstrung by the associations of the traditional name of our condition. That a new name can offer more social opportunities to those labelled by it is shown by the case of Down syndrome. Since this term was introduced, people with Down syndrome are treated with greater respect and better accepted in society.

At the end of the 19th century the German professor of psychiatry Emil Kraepelin (1856-1926) introduced the term 'dementia praecox' (premature dementia) to distinguish this potentially psychotic condition from manic depression. At the beginning of the twentieth century the Swiss professor of psychiatry Eugen Bleuler (1857-1939) replaced that term by 'schizophrenia' (Louter, 2010). Since Bleuler's time much has changed.

In our view the name 'schizophrenia' is out of date and out of touch with modern science: partly through medication people with 'schizophrenia' can now participate in society much more easily than they could a century ago; furthermore, the name 'schizo-phrenia' suggests a split personality, which has nothing to do with our potentially psychotic condition. Various parties are now making proposals for a new name for schizophrenia that fits a modern (scientific) understanding. Japan played the first card. Hong Kong, Korea and China are following suit.

In 2009 the Dutch patient society Anoiksis, recognizing the need to find a better name, held a competition. The winning name out of 320 entries was Dysfunctional Perception Syndrome, or DPS. Immediately there was criticism of this name too: a person wearing spectacles also has dysfunctional perception; you can make of DPS Dual Personality Syndrome; and 'dysfunctional syndrome' is a tautology...y you do not talk about 'dysfunctional metabolic syndrome' but about 'metabolic syndrome'.

The chair of the appropriate DSM-5 (Diagnostic and Statistical Manual of Mental Disorders) work group of the American Psychiatric Association, Will Carpenter, wrote to us in an e-mail on 20 October 2012:

Stigma is a problem for many reasons. A name change may be helpful, but a name change needs universal use and should be worked out by a properly constituted work group comprising the relevant stakeholders making a recommendation to the International Classification of Diseases (ICD) and DSM processes. I think it would be proper for the World Health Organisation (WHO) to use its convening authority to address this issue [quoted with permission].

The choice of a new name is under vigorous discussion globally (van Os, 2009; George, 2010a, b). Anoiksis is now campaigning internationally for the term 'Psychosis Susceptibility Syndrome' (PSS). 'Psychosis' because it covers the unreality of both hallucinations and delusions. 'Susceptibility' because a person with schizophrenia is in many cases not psychotic all the time. 'Syndrome' because it includes the negative and cognitive symptoms that are significant elements of this whole complex condition.

'Negative symptoms' refer to deficiencies in a function that is normally present, such as affective flattening (emotional distance, loss of feelings), apathy (lack of energy, initiative and interest), asociality (avoiding company, diminished awareness of the environment, greater need to be alone), anhedonia (loss of ability to experience pleasure), alogia (poverty of speech), lack of perseverance and feeling empty (cf. Lewis et al. 2009).

By the 'cognitive symptoms' we think of attention deficit, poor memory leading to inefficiency at work or school, indecision, difficulty solving problems and making plans, lack of ability to interpret body language (cf. Haycock, 2009). People can in severe cases become so disorganized that they need to live in a hospital.

Moreover, many of us have difficulties connecting to other people. This reflects precisely what we experience. Besides the grief of the impoverishment of mental life and lost mental and practical abilities, we have to deal with stigma that our behaviour (or nonbehaviour) evokes. We are lazy, uninterested and not motivated to work, they say. People tend to attribute the above groups of symptoms to the personality of a person; that is why it is so important to educate society. Life with our 'disease' is tough enough without having to cope with stigma in addition.

The discussion about the label provides us with an opportunity to relate what 'schizophrenia' is actually about. As far as Anoiksis' outreach is concerned this is our most important task: to continue to disclose an open and honest account of our condition in order to set up a virtuous circle. That fits with the tenor of the research by Evans-Lacko et al. (2012). Providing better information about mental illness and facilitating direct social contact in order to lessen the stigmatizing by the general public will also enable us patients to form a healthier image of ourselves.

\section{Declaration of Interest}

The authors are Anoiksis Foreign Affairs co-coordinators.

\section{References}

Corrigan P, River L, Lundin R, Penn D, Uphoff-Wasowski K, Campion J, Mathisen J, Gagnon C, Bergman M, Goldstein H, Kubiak M (2001). Three strategies for 
changing attributions about severe mental illness. Schizophrenia Bulletin 27, 187-195.

Evans-Lacko S, Brohan E, Mojtabai R, Thornicoft G (2012). Association between public views of mental illness and self-stigma among individuals with mental illness in 14 European countries. Psychological Medicine 42, 1741-1752.

George B (2010a). Viewpoint. A less stigmatising name for schizophrenia. Mental Health Today March, 35.

George B (2010b). What's in a name? Client participation, diagnosis and the DSM-5 [Editorial]. Journal of Mental Health 19, 479-482.

Haycock D (2009). Symptoms of schizophrenia. Netplaces (http://www.netplaces.com/schizophrenia/symptoms-ofschizophrenia/cognitive-problems.htm). Accessed 10 March 2013.

Lewis S, Escalona P, Keith S (2009). Phenomenology of schizophrenia. In: Kaplan and Sadock's Comprehensive Textbook of Psychiatry, 9th edn (ed. B. Sadock, P. Sadock and P. Ruiz), pp. 1443-1447. Lippincott, Williams \& Wilkins: Philadelphia.

London J, Evans-Lacko S (2010). Challenging mental health-related stigma through social contact. European Journal of Public Health 20, 130-131.

Louter M (2010). Schizophrenia: what's in a name? Mental Health Practice 13, 28-30.

Muis M (ed.) (2010). SKIZ'O: Het NORMAALSTE magazine van Nederland. Vereniging Anoiksis: Utrecht.

Muis M (2011). Meer dan dat. . 10 portretten van mensen met schizofrenie. Tobi Vroegh: Amsterdam.

Sato M (2006). Renaming schizophrenia. A Japanese perspective. World Psychiatry 5, 53-55.

Thornicroft G (2011). Mental Illness Stigma Symposium. Carleton University Videos, Canada.

van Os J (2009). 'Salience syndrome' replaces 'schizophrenia' in DSM-5 and ICD-11: psychiatry's evidence-based entry into the 21st century? Acta Psychiatrica Scandinavica 120, 363-372.

BILL GEORGE AND AADT KLIJN

Anoiksis Think Tank, Utrecht, The Netherlands

(Email: bill.george@planet.nl) [B. George]

Anoiksis, Gansstraat 67a, 3582 EC Utrecht,

The Netherlands

For further details visit: www.anoiksis.nl (click on the flag for English)

Psychological Medicine (2013).

doi:10.1017/S0033291713000901

\section{Forum}

Renaming schizophrenia coupled with proper public education is an optimal way to overcome stigma

In Japan, the name of Seishin Bunretsu Byo (mind-split disease), a direct translation of schizophrenia, has been replaced with Togo-Shitcho Sho (integration dysregulation syndrome) since 2002 (Sato, 2006). The new name has been widely accepted in society; Togo-Shitcho Sho has been used in bureaucratic documents, the media, and published materials, as well as in clinical settings. After the official announcement about renewing the name, the proportion of patients who were informed of their diagnosis by attending physicians rose: from $37 \%$ in a year before the introduction to $65 \%$ in the following year. This reflects the fact that over $80 \%$ of Japanese psychiatrists reported that the new name was easier to convey to patients afflicted with the condition compared with the old term (Sato, 2006). In addition, the majority of Japanese psychiatrists were found to be affirmative in documenting that the new name serves to improve treatment compliance, and to ameliorate the ill image of the disorder shrouded by stigma (Sato, 2006). These are, at least in part, attributable to the erroneously built-in impression the old term bears; in a survey conducted in Tokyo, college students were more likely to relate the previous label to criminal conducts than the new name (Takahashi et al. 2009). Thus, the introduction of the new term, which has been welcomed by patients themselves as well as mental health professionals and the public, may be beneficial in the context of a public health perspective and acceptance by the community.

However, merely renaming the disease may not be sufficient, since a change of name does not resolve the deep-rooted stigma; for instance, the public's ignorance of the true nature of the disease and fear of people with a condition of schizophrenia have been pointed out (Lieberman \& First, 2007). In this respect, we are in agreement with the point made by George \& Klijn (2013) that public education is important in reducing stigma. If the label were replaced with a different one, fallacious knowledge about the content would not be rectified.

The importance of public education about mental disorders is exemplified by autism. The term 'autism' was named, by Hans Asperger in 1938, after Bleuler who had used this term to describe one aspect of the features of schizophrenia. This term is still in use among mental health professionals, education and welfare officials, and the public. There was little public awareness of autism until recently. The disorder was easily overlooked or had been attributed to bad parenting. Some individuals with autism were even misdiagnosed as having schizophrenia (Sugihara et al. 2008). However, the characteristics and unique brain functioning in autism have been featured in a variety of the media, including TV programmes, movies, books, and newspapers in Japan. Accordingly, this has led to increased awareness of autism in the public. In tandem with this movement, professionals in the field of mental health, education and social welfare have 